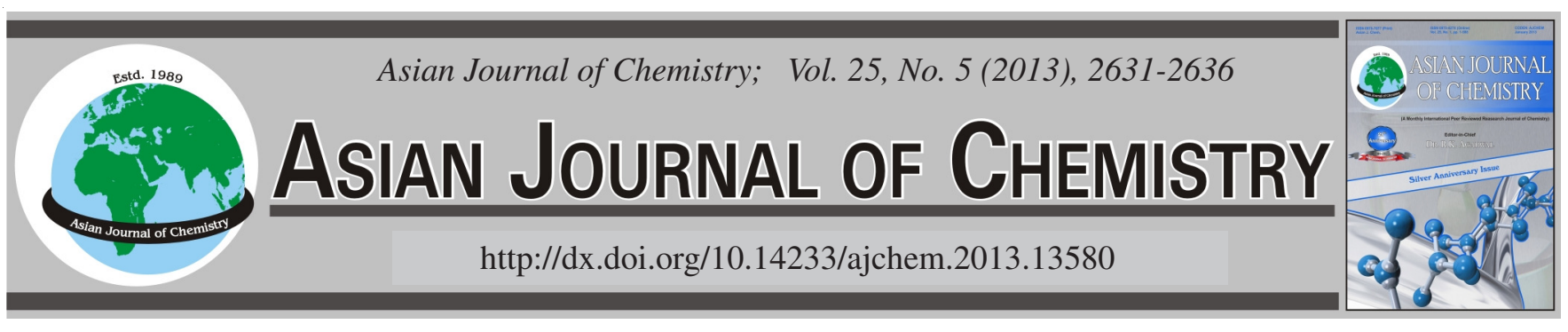

\title{
Granular Activated Carbon Adsorption Process for Removing Methyl tert-Butyl Ether from Groundwater
}

\author{
JuAn Hu, Liu-Ya Huang, Bing-Jing Li, Wei Zhang* and Wei-Chi Ying
}

State Environmental Protection Key Laboratory of Environmental Risk Assessment and Control on Chemical Process, School of Resources and Environmental Engineering, East China University of Science and Technology, Shanghai 200237, P.R. China

*Corresponding author: E-mail: zhangwei@ecust.edu.cn

(Received: 10 February 2012;

Accepted: 15 November 2012)

AJC-12417

\begin{abstract}
Methyl tert-butyl ether (MTBE), a popular organic solvent and gasoline additive, has become a common groundwater pollutant. Extensive batch adsorption isotherm experiments and continuous flow breakthrough experiments were conducted to identify the most attractive granular activated carbon (GAC) and to determine the effects of important factors governing the GAC treatment effectiveness. The organic constituents of the test solution reduced the GAC's capacity for MTBE in pure water and that the reduction was dependent on both the solution composition and the GAC's pore structure. GAC's phenol number is a useful indicator of its adsorptive capacity for MTBE. MTBE breakthrough data confirmed the relative isotherm capacities and illustrated the better capacity utilization of using two serial adsorbers relative to a larger adsorber holding the combined amount of GAC. The environmental friendly bamboo JHBG1 was the most cost effective of 7 GACs studied. The GAC adsorption treatment is practical for removing a small quantity of MTBE from groundwater; biodegradation of MTBE in the adsorber will enable its long term service without periodic GAC replacement.
\end{abstract}

Key Words: Methyl tert-butyl ether, Granular activated carbon, Adsorptive capacity, Capacity reductions.

\section{INTRODUCTION}

Methyl tert-butyl ether (MTBE) is a popular organic solvent and the most popular octane enhancer of unlead gasoline. Since its first use in 1970s, its worldwide consumption has exceeded $240 \times 10^{6} \mathrm{~L} /$ year and is the second most often found groundwater pollutant (found in $27 \%$ of samples) in the United States ${ }^{2}$. Due to its high water solubility (50000 $\mathrm{mg} / \mathrm{L}$ at $20^{\circ} \mathrm{C}$ ) and mobility, low volatility, biodegradability and affinity for soil ${ }^{3}$, MTBE remains in groundwater and presents a health concern for a long time primarily due to its low thresholds of taste $(40 \mu \mathrm{g} / \mathrm{L})$ and odor $(20 \mu \mathrm{g} / \mathrm{L})^{4.5}$. The concentration of MTBE in groundwater around leaking underground storage tanks and/or other newly contaminated sites can be rather high, up to $100 \mathrm{mg} / \mathrm{L}$; it decrease to few $\mathrm{mg} / \mathrm{L}$ due to the horizontal and vertical transport with groundwater in first three months ${ }^{6}$. Because of the rapidly growing gasoline consumption in China, MTBE will soon become a major groundwater pollutant in $\mathrm{China}^{7}$.

Granular activated carbon (GAC) is a powerful adsorbent for removing organic pollutant from water. The treatment effectiveness is dependent both on its pore structure and the pollutant characteristics. Although GAC have been successfully employed for removing MTBE in both lab studies and practice $^{8-11}$; however, information on the selection of the best GAC and the most cost effective adsorption treatment are still lacking.

Our lab have developed simple GAC selection and application methods demonstrating that GAC's pore structure (specific surface area and pore volume distribution $v s$. pore diameter profiles) are well correlated with its four adsorptive capacity indicators (phenol, iodine, methylene blue and tannic acid numbers) and that the micro column rapid breakthrough (MCRB) method was capable of producing the desired pollutant breakthrough curves for simulating full scale treatment performance of the on-site GAC adsorbers in a small fraction of time that would be necessary using the conventional method $^{12-14}$.

This study was performed to evaluate the feasibility of employing GAC adsorption for removing MTBE from groundwater with the following objectives: (1) compare the adsorptive capacities of GACs of different raw material and activation methods for MTBE, (2) correlate the GAC's MTBE capacity with one of the capacity indicators, (3) determine the effects of GAC's pore structure and solution composition on its isotherm capacity, (4) conduct continuous flow breakthrough experiments to verify the isotherm study results and to simulate the full scale GAC treatment effectiveness, (5) propose 
the most cost effective adsorption treatment process and (6) estimate the GAC cost for a typical remediation case of MTBE removal.

\section{EXPERIMENTAL}

This study employed a total of seven commercial GACs: two made from coal (SYC \& Calgon F300), two from coconut shells (SYK \& Norit GCN 830) and three from bamboo (SBG, JHBG1 \& JHBG2). SYK and SBG were obtained from Shanghai GAC Co. (China); JHBG1 \& JHBG2 were from Jinhu Carbon Co. (China). Greater effort was made to evaluate the three bamboo GACs because of their environmental friendly nature of being produced from a readily available, low cost, renewable natural resource in the less polluting manufacturing process. The GAC samples were prepared for the isotherm (200-325 mesh) and the MCRB (120-180 mesh) runs ${ }^{13}$. The reagent grade MTBE was obtained from a local lab supplier. Distilled and de-ionized (pure) water (TOC $<0.4 \mathrm{mg} / \mathrm{L}$ ), prepared by Purelab Classic DI System (ELGA,UK), dechlorinated tap water $\mathrm{TOC}=4.5 \mathrm{mg} / \mathrm{L}$ ), produced by passing through a small activated carbon column and well water (TOC $=8.8 \mathrm{mg} / \mathrm{L}$ ), obtained from a local well to simulate the urban groundwater, samples were employed to prepare the MTBE solutions for the isotherm and breakthrough experiments. Analytical grade iodine, phenol, methylene blue and tannic acid were obtained from local suppliers.

Equipments and chemical analysis: The concentrations of iodine, phenol, methylene blue and tannic acid solutions were measured by UV/visible absorbance at 600, 268, 613 and $275 \mathrm{~nm}$, respectively.

The purge and trap sample concentrator (Tarkmar) coupled with GC-FID system (Agilent 7890) were used to extract MTBE from $5 \mathrm{~mL}$ aqueous sample for $5 \mathrm{~min}$ at the ambient temperature. Nitrogen was used as purge gas at a flow rate of $60 \mathrm{~mL} / \mathrm{min}$ and as carry gas in GC system. The transfer line were heated to $140^{\circ} \mathrm{C}$ and desorbed at $250^{\circ} \mathrm{C}$ for 2 min to GC-FID. The GC-FID method used a DB-32 capillary column (Agilent, DB-35MS, $60 \mathrm{~m} \times 0.35 \mathrm{~mm} \times 0.25 \mu \mathrm{m}$ ) with an injector temperature of $300{ }^{\circ} \mathrm{C}$ and a column temperature at $50{ }^{\circ} \mathrm{C}$ to keep $1 \mathrm{~min}$ and a ramp of $15^{\circ} \mathrm{C} / \mathrm{min}$ to $100{ }^{\circ} \mathrm{C}$ for 3 $\mathrm{min}$. The air flow rate and hydrogen flow rate are $400 \mathrm{~mL} / \mathrm{min}$ and $30 \mathrm{~mL} / \mathrm{min}$, respectively.

Adsorptive capacity indicator and batch isotherm experiments: Test runs were first conducted to obtain the four adsorptive capacity indicators for each GAC using the estab- lished procedures ${ }^{14}$. A high phenol number indicates the GAC has a large internal surface area of smallest micropores (diameter $<1 \mathrm{~nm}$ ) and a low surface acidity which enhances adsorption of polar organic compounds; high values of iodine number, methylene blue number and tannic acid number indicate the same of small micropores (diameter $<1.5 \mathrm{~nm}$ ), large micropores $($ diameter $=1.5-2.8 \mathrm{~nm}$ ) and larger pores (diameter $>2.8 \mathrm{~nm}$ ), respectively. Table-1 presents the four adsorptive capacity indicators of the 7 GACs.

Batch isotherm experiments were performed on MTBE solutions of various initial concentration $(0.5-10 \mathrm{mg} / \mathrm{L})$ and of different water composition (in pure, tap and well water samples) employing the standard procedures for contacting the carbon particles (1-8 mg of 200-325 mesh) and the MTBE solution in a filled $42 \mathrm{~mL}$ glass bottle. After the carbon particles and the MTBE solution was mixed for at least $2 \mathrm{~h}$ to establish the equilibrium between the liquid and solid phases; the supernatant was taken for MTBE measurement after allowing the particles to settle.

The adsorptive capacity was calculated by: $\mathrm{X} / \mathrm{M}(\mathrm{mg} / \mathrm{g})=\left(\mathrm{C}_{0}-\mathrm{C}_{\mathrm{f}}\right) \mathrm{V} /$ carbon dose $(\mathrm{g})$

where $\mathrm{X} / \mathrm{M}$ is adsorptive capacity $(\mathrm{mg} / \mathrm{g}), \mathrm{C}_{0}$ and $\mathrm{C}_{\mathrm{f}}$ are the initial and final MTBE concentration $(\mathrm{mg} / \mathrm{L})$, respectively and $\mathrm{V}$ is the sample volume $(\mathrm{L}) . \mathrm{X} / \mathrm{M}$ and $\mathrm{C}_{\mathrm{f}}$ data were correlated by Freundlich adsorption isotherm model ${ }^{15,16}$.

Continuous flow adsorption breakthrough experiments: Continuous flow adsorption breakthrough experiments were performed using the MCRB method which was evolved from the USEPA's rapid small scale column test (RSSCT) techniques $^{17}$. Compared to RSSCT technique, the MCRB method has such improvements as smaller GAC particles and less amount employed, simplified system, lower pressure rating of the pump and shorter time to get breakthrough. The MCRB runs were conducted at two empty bed contact time (EBCT) of 5 and $10 \mathrm{~s}$ which would simulate the breakthrough curve of a full size adsorber operating at an empty bed contact time of 8 and $16 \mathrm{~min}\left(\mathrm{~d}_{120-180} \mathrm{mesh}=0.1 \mathrm{~mm}\right.$ and $\mathrm{d}_{8 \times 30}=1.0 \mathrm{~mm}$, the run time ratio was about $0.01^{18}$. The operation conditions are listed in Table-2. The column effluent samples were taken periodically for measurement of MTBE concentrations which were plotted against the bed volume treated in the dimensionless form of $\mathrm{C} / \mathrm{C}_{\mathrm{in}}\left(\mathrm{C}_{\mathrm{in}}\right.$ is the influent MTBE concentration) to show the observed breakthrough curves from which the capacity utilization rates at three effluent objectives of 0.02 , 0.5 and 0.70 were estimated.

\begin{tabular}{|c|c|c|c|c|c|c|c|}
\hline \multirow{3}{*}{ Carbon } & \multicolumn{7}{|c|}{$\begin{array}{c}\text { TABLE-1 } \\
\text { CAPACITY INDICATORS AND MTBE REMOVAL EF }\end{array}$} \\
\hline & \multirow{2}{*}{$\begin{array}{l}\text { Phenol } \\
\text { number }^{\mathrm{a}}\end{array}$} & \multirow{2}{*}{$\begin{array}{l}\text { Iodine } \\
\text { number }\end{array}$} & \multirow{2}{*}{$\begin{array}{l}\text { Methylene blue } \\
\text { number }\end{array}$} & \multirow{2}{*}{$\begin{array}{l}\text { Tannic acid } \\
\text { number }^{\mathrm{d}}\end{array}$} & \multicolumn{3}{|c|}{ Capacity at $\mathrm{Ce}=1 \mathrm{mg} / \mathrm{L}^{\mathrm{e}}(\mathrm{mg} / \mathrm{g})$} \\
\hline & & & & & Pure & Тар & Well \\
\hline JHBG1 & 112 & 984 & 277 & 20 & 15.0 & 5.80 & 7.05 \\
\hline JHBG2 & 107 & 1138 & 290 & 24 & 9.21 & 4.83 & 5.46 \\
\hline SBG & 94 & 1163 & 237 & 20 & 2.80 & 2.56 & 2.70 \\
\hline GCN 830 & 116 & 1204 & 279 & 13 & 5.34 & 4.12 & 2.83 \\
\hline SYK & 106 & 1154 & 303 & 13 & 4.06 & 3.07 & 2.45 \\
\hline F300 & 104 & 1125 & 281 & 27 & 3.95 & 3.00 & 3.05 \\
\hline SYC & 53 & 998 & 262 & 32 & 1.51 & 1.35 & 1.83 \\
\hline
\end{tabular}

${ }^{\mathrm{a}} \mathrm{Mg}$ of phenol adsorbed by $1 \mathrm{~g}$ of carbon in a $20 \mathrm{mg} / \mathrm{L}$ phenol solution. ${ }^{\mathrm{b}} \mathrm{Mg}$ of iodine adsorbed by $1 \mathrm{~g}$ of carbon in a $0.02 \mathrm{~N}$ iodine solution. ${ }^{\mathrm{c}} \mathrm{Mg}$ of methylene blue adsorbed by $1 \mathrm{~g}$ of carbon in a $1 \mathrm{mg} / \mathrm{L}$ methylene blue solution. ${ }^{\mathrm{d}} \mathrm{Mg}$ of tannic acid adsorbed by $1 \mathrm{~g}$ of carbon in a $2 \mathrm{mg} / \mathrm{L}$ tannic acid soluton. ${ }^{\circ}$ Calculated from the Freundlich adsorption isotherm at $\mathrm{Ce}=1 \mathrm{mg} / \mathrm{L}$. 
TABLE-2

SUMMARY OF THE 15 MCRB RUNS OF REMOVING MTBE FROM AQUEOUS INFLUENT

\begin{tabular}{|c|c|c|c|c|c|c|c|c|c|}
\hline \multirow{2}{*}{ MCRB run } & \multirow{2}{*}{$\begin{array}{l}\text { Flowrate/EBCT } \\
\left(\mathrm{mL} \mathrm{min}^{-1} / \mathrm{s}\right)\end{array}$} & \multirow{2}{*}{$\begin{array}{l}\text { Influent Conc./MTBE } \\
\text { Supplied }^{\mathrm{a}}\left(\mathrm{mg} \mathrm{L}^{-1} \mathrm{mg}\right)\end{array}$} & \multirow{2}{*}{$\begin{array}{l}\text { Amount of } \\
\text { GAC }(g)\end{array}$} & \multirow{2}{*}{$\begin{array}{l}\text { Removal } \\
\text { rate }^{\mathrm{b}}\end{array}$} & \multirow{2}{*}{$\begin{array}{c}\text { MTBE } \\
\text { Removed }^{\mathrm{c}}(\mathrm{mg})\end{array}$} & \multirow{2}{*}{$\begin{array}{c}\text { MTBE } \\
\text { capacity }^{\mathrm{d}}(\mathrm{mg})\end{array}$} & \multicolumn{3}{|c|}{ Capacity utilization $^{\mathrm{e}} \mathrm{C} / \mathrm{C}_{\mathrm{in}}$} \\
\hline & & & & & & & 0.02 & 0.50 & 0.70 \\
\hline $\mathrm{JHBG}^{\mathrm{f}}$ & $6.0 / 4.91$ & $1.113 / 2.60$ & 0.4004 & 0.56 & 1.46 & 2.33 & 4.20 & 35.70 & 56.89 \\
\hline $\mathrm{JHBG}^{\mathrm{g}}{ }^{\mathrm{g}}$ & $6.6 / 5.00$ & $1.117 / 2.89$ & 0.3999 & 0.63 & 1.82 & 2.84 & 1.50 & 47.44 & 50.35 \\
\hline $\mathrm{JHBG} 2^{\mathrm{f}}$ & $8.2 / 5.03$ & $1.111 / 2.37$ & 0.4004 & 0.36 & 0.85 & 2.06 & 1.01 & 28.40 & 36.24 \\
\hline $\mathrm{JHBG} 2^{\mathrm{g}}$ & $8.6 / 5.03$ & $1.328 / 3.19$ & 0.3009 & 0.58 & 1.85 & 2.18 & 2.50 & 49.64 & 69.44 \\
\hline $\mathrm{SBG}^{\mathrm{g}}$ & $6.1 / 5.00$ & $1.328 / 2.79$ & 0.3996 & 0.45 & 1.26 & 1.11 & 4.20 & 69.21 & 95.95 \\
\hline $\mathrm{F} 300^{\mathrm{g}}$ & $6.6 / 507$ & $0.927 / 2.56$ & 0.4040 & 0.45 & 1.16 & 1.23 & 9.80 & 64.58 & 89.16 \\
\hline $\mathrm{SYC}^{\mathrm{g}}$ & $6.7 / 4.92$ & $0.909 / 2.63$ & 0.024 & 0.54 & 0.76 & 0.74 & 6.00 & 57.20 & 87.62 \\
\hline GCN $830^{\mathrm{g}}$ & $7.2 / 4.97$ & $0.936 / 2.34$ & 0.4018 & 0.61 & 1.42 & 1.97 & 12.52 & 53.57 & 71.96 \\
\hline $\mathrm{SYK}^{\mathrm{g}}$ & $6.8 / 4.85$ & $0.956 / 2.08$ & 0.4030 & 0.56 & 0.92 & 0.99 & 13.67 & 51.37 & 68.36 \\
\hline GCN $830^{f}$ & $2.4 / 9.82$ & $1.083 / 1.94$ & 0.4006 & 0.77 & 1.49 & 1.65 & 14.76 & 70.90 & 78.95 \\
\hline GCN $830^{\circ}$ & $2.2 / 10.17$ & $1.149 / 2.11$ & 0.4026 & 0.65 & 1.37 & 1.97 & 17.25 & 66.17 & 76.68 \\
\hline$F 300^{f}$ & $4.2 / 9.82$ & $1.080 / 2.15$ & 0.5008 & 0.63 & 1.35 & 1.50 & 31.22 & 62.27 & 68.30 \\
\hline $\mathrm{F} 300^{\mathrm{g}}$ & $4.6 / 10.04$ & $1.111 / 2.15$ & 0.5009 & 0.70 & 1.51 & 1.54 & 30.64 & 66.74 & 87.40 \\
\hline $\mathrm{SBG}^{\mathrm{f}}$ & $3.5 / 10.10$ & $1.061 / 1.42$ & 0.4001 & 0.53 & 0.75 & 1.03 & 4.20 & 43.65 & 71.34 \\
\hline $\mathrm{SBG}^{\mathrm{g}}$ & $3.5 / 10.10$ & $1.082 / 1.37$ & 0.3994 & 0.67 & 0.92 & 1.11 & 5.00 & 67.67 & 93.21 \\
\hline
\end{tabular}

${ }^{a}$ Total MTBE supplied $=\left(\right.$ EBCT $\times$ bed volume number $\times$ MTBE $_{\text {in }} \times$ flow rate $)(60 \times 1000) .{ }^{b}$ Removal rate $=$ area above the breakthrough curve/total area of the run. ${ }^{c}$ MTBE removed $=$ MTBE supplied $\times$ removal rate. ${ }^{d}$ MTBE capacity $=$ carbon amount $\times \mathrm{XM}$ at $\mathrm{MTBE}_{\mathrm{in}}(\mathrm{estimated}$ from

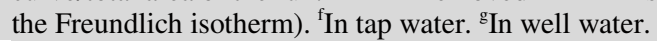

\section{RESULTS AND DISCUSSION}

Factors affecting GAC's capacity for MTBE: To obtain valid isotherm data for estimating adsorptive capacity for a wide range of equilibrium concentration, often require many series of isotherm runs employing different initial concentration of the adsorbate which, however, may result in different isotherms ${ }^{19}$. Fig. 1 presents the isotherm capacities of the 7 GACs for MTBE in pure water employing solutions of different initial concentrations $(0.5-10 \mathrm{mg} / \mathrm{L})$. Given that one overall straight line can adequately represent the three data sets, the initial concentration of this study did not significantly affect the MTBE isotherms in the pure water environment. Fig. 2 presents the isotherm capacities of GCN830 and SYK (coconut shell based) and F300 (coal based) for MTBE in well water employing different initial concentrations $(0.5,1.0,2.0$ and $10.0 \mathrm{mg} / \mathrm{L}$ ). The smaller adsorption capacity found in the lower MTBE initial concentration runs was due to their \% TOC of the well water sample ${ }^{20}$. That the similar capacity reduction patterns of the two coconut GACs is notably different from

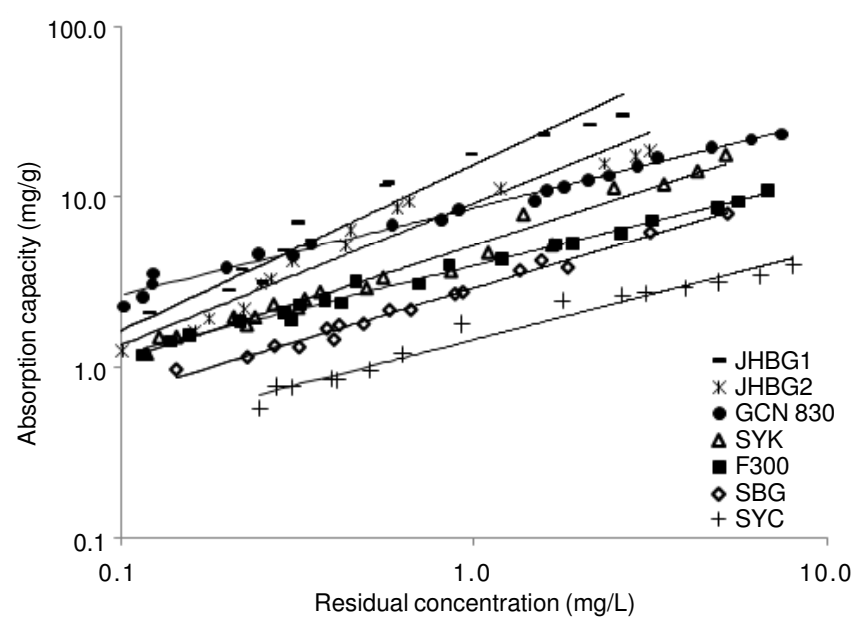

Fig. 1. Freundlich isotherms of GACs' adsorptive capacities for MTBE in pure water $(\mathrm{Co}=0.5-10 \mathrm{mg} / \mathrm{L})$

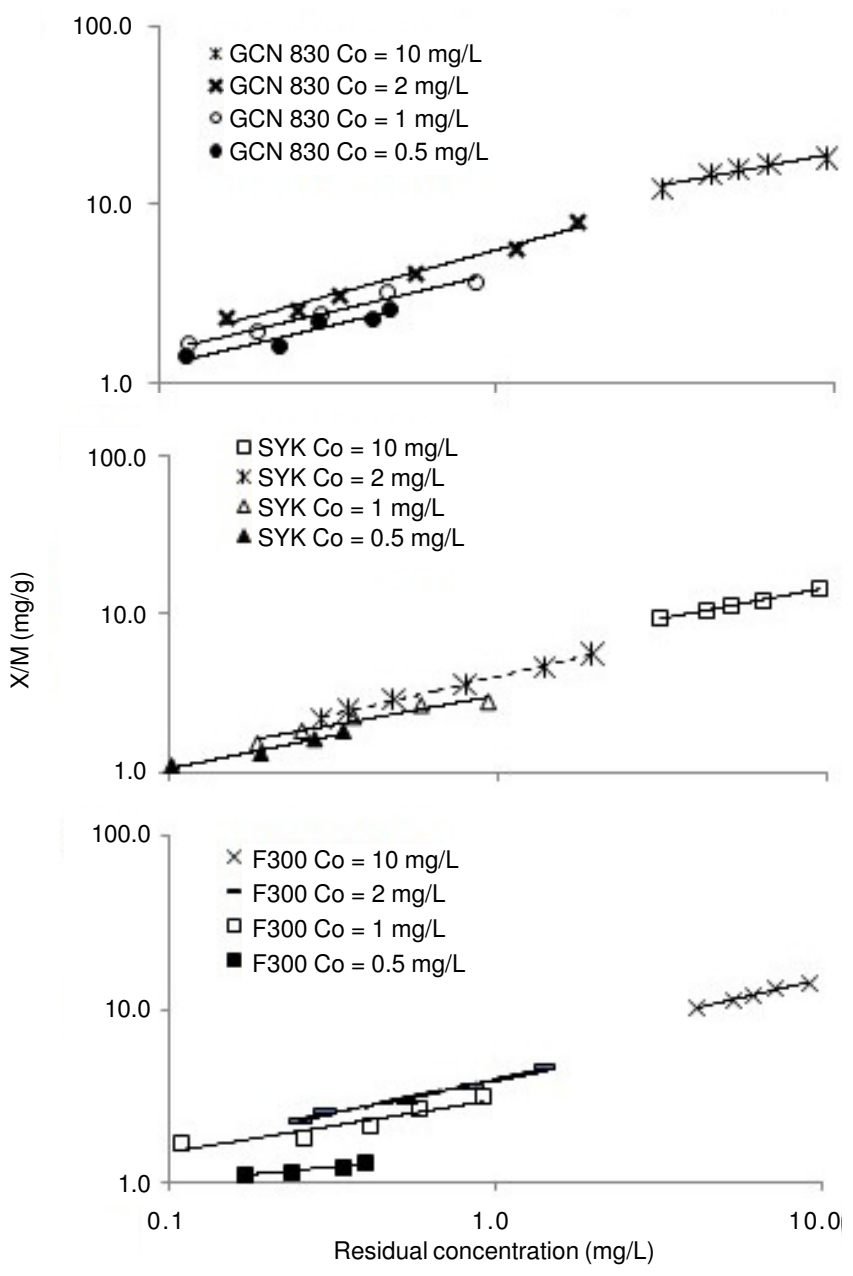

Fig 2. GACs' adsorptive capacities for MTBE in well water

that of the coal GAC is another evidence of the significant effect of GAC's pore structure on its adsorptive capacity for a specific water pollutant.

Table-3 presents the Freundlich model representation of the well water isotherm data of the 7 GACs as well as their 
TABLE-3

FREUNDLICH ISOTHERMS OF THE GACS' CAPACITIES FOR MTBE IN WELL WATER (Co $=10 \mathrm{mg} / \mathrm{L})$ AND THEIR ADSORPTIVE CAPACITIES AND EXHAUSTION RATES FOR 4 INFLUENT CONCENTRATION

\begin{tabular}{|c|c|c|c|c|c|c|c|}
\hline \multirow{2}{*}{ GAC } & \multicolumn{3}{|c|}{ Model Parameters $^{\mathrm{a}}$} & \multicolumn{4}{|c|}{ Adsorptive capacity $/$ minimum exhaustion rate ${ }^{\mathrm{c}}$} \\
\hline & $\mathrm{K}$ & $1 / \mathrm{n}$ & $\mathrm{R}^{2}$ & $0.5 \mathrm{mg} / \mathrm{L}^{\mathrm{d}}$ & $1.0 \mathrm{mg} / \mathrm{L}$ & $3.0 \mathrm{mg} / \mathrm{L}$ & $8.0 \mathrm{mg} / \mathrm{L}$ \\
\hline JHBG1 & 6.9311 & 0.5162 & 0.9874 & $4.84 / 0.10$ & $6.93 / 0.14$ & $12.22 / 0.25$ & $20.28 / 0.39$ \\
\hline JHBG2 & 6.0321 & 0.4719 & 0.9627 & $4.35 / 0.11$ & $6.03 / 0.17$ & $10.13 / 0.30$ & $16.09 / 0.50$ \\
\hline SBG & 3.0372 & 0.6578 & 0.9730 & $1.93 / 0.26$ & $3.04 / 0.33$ & $6.26 / 0.48$ & $11.93 / 0.67$ \\
\hline GCN 830 & 5.0792 & 0.5413 & 0.9800 & $3.49 / 0.14$ & $5.08 / 0.20$ & $9.21 / 0.33$ & $15.65 / 0.51$ \\
\hline SYK & 4.3340 & 0.5321 & 0.9711 & $3.00 / 0.17$ & $4.33 / 0.23$ & $7.78 / 0.39$ & $13.10 / 0.61$ \\
\hline F300 & 4.1459 & 0.5492 & 0.9845 & $2.83 / 0.18$ & $4.15 / 0.24$ & $7.58 / 0.40$ & $12.99 / 0.62$ \\
\hline SYC & 1.4618 & 0.5248 & 0.9680 & $1.02 / 0.49$ & $1.41 / 0.68$ & $2.60 / 1.15$ & $4.35 / 1.84$ \\
\hline
\end{tabular}

${ }^{a} \mathrm{R}^{2}$ : correlation coefficient of the Freundlich isotherm model. ${ }^{\mathrm{b}}$ Based on the Freundlich isother, $\mathrm{M} / \mathrm{M}(\mathrm{mg} / \mathrm{g})=\mathrm{kC}{ }^{1 / \mathrm{n}}$. ${ }^{\mathrm{c}}$ Minimum exhaustion rate $(\mathrm{g} / \mathrm{L})=\mathrm{C}_{\mathrm{in}} / \mathrm{X} / \mathrm{M}$ at $\mathrm{C}_{\mathrm{in}} \cdot{ }^{\mathrm{d}}$ Influent concentration $\mathrm{C}_{\text {in }}$

adsorptive capacities and minimum exhaustion rates for removing MTBE from groundwaters of different contamination levels. The data clearly demonstrate that the GAC's adsorptive capacity for MTBE was dependent on its raw material and the activation method. Both coconut GCN830 and SYK have higher capacities than the well known coal F300; the two new bamboo JHBG1 and JHBG2 exhibited much higher MTBE capacities than the more available bamboo SBG, which performed better than Calgon F300 and F400 in our recent study of GAC adsorption for removing trichloroethylene ${ }^{21}$, suggesting that further $\mathrm{R}$ and $\mathrm{D}$ may result in a more cost effective environmental friendly bamboo GAC.

Indicator of MTBE adsorption on GAC: Granular activated carbon's adsorptive capacity for a water pollutant is dependent both on its pore structure and the water composition; the former is governed by the adsorbent's raw material and its manufacturing process while the latter is affected by the other organic constituents of the water sample. The four adsorptive capacity indicators (phenol, iodine, methylene blue and tannic acid numbers) have been employed successfully to characterize the GAC's porous structure and its relative adsorptive capacities for water pollutants of different size $\mathrm{e}^{12,14}$. The phenol number was found to be a good indicator of MTBE capacity in an earlier study ${ }^{21}$ and that the tannic acid number a good indicator of capacity utilization in adsorption treatment for removing trichloroethylene ${ }^{21}$. Test runs were conducted to obtain the four capacity indicators of the GAC samples and to compare their MTBE removal effectiveness. Table-1 presents the four capacity indicators of the $7 \mathrm{GACs}$ and their relative adsorptive capacities for removing MTBE from pure water, tap water and well water influents based on the respective MTBE isotherms.

The results of this study have confirmed the use of phenol number as the indicator of GAC's MTBE capacity, which is consistent with the facts that they are both fast diffusing, polar organic compounds of similar molecular weight (94.2 for phenol and 88.4 for MTBE) and the same molecular diameter of $0.62 \mathrm{~nm}^{22,23}$. It is worthy to note that the same order of MTBE capacities was preserved for the test runs employing the tap water and well water based solution.

Effects of natural organic matter (NOM) on MTBE adsorption: The tap water and well water samples contained many natural organic matters (NOMs) which came naturally from decaying plant tissues. Natural organic matters are mostly large organic compounds of molecular weights ranging from $<1000$ to $>10,000$; the larger ingredients are often removed in the water treatment plant making the tap water NOM species on the average much smaller than those of the well water samples. This study employed several 1-10 mg/L MTBE solutions prepared in pure water, tap water and well water to evaluate the effects of NOMs on the MTBE isotherm capacities and the capacity utilization in the continuous flow breakthrough experiments.

Fig. 3 presents the MTBE isotherms of $\mathrm{F} 300$ and GCN830 showing the effect of the NOMs in tap water and well water on reducing the pure water MTBE capacity. The estimated MTBE capacity for removing $1 \mathrm{mg} / \mathrm{L}$ of MTBE in pure, tap and well influents (Table-1) demonstrates that the NOMs of the water samples affected the reductions from its pure water isotherms. For the coconut GCN830 and SYK having low tannic acid numbers, greater reductions were found in the higher TOC well sample since its NOMs caused more blocked intraparticle pores than the NOMs of the tap water sample; for the four other GACs having higher tannic acid numbers, most NOMs of the tap water sample were able to reach the adsorption sites of the small micropores resulting in a greater capacity reduction due to competitive adsorption of its smaller organic constituents relative to that reduced by well water NOMs which were too large to enter the micropores ${ }^{24}$.

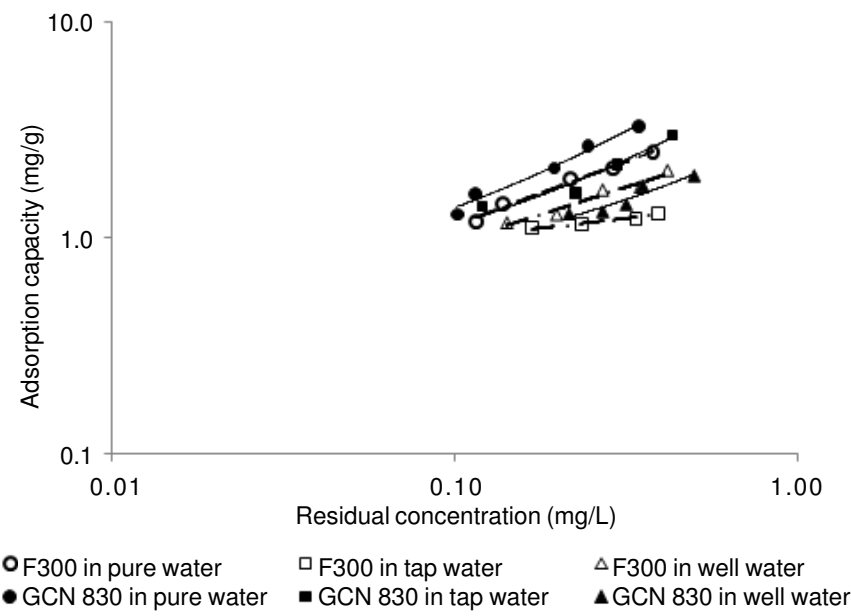

Fig. 3. Effect of NOM on MTBE adsorption isotherms $(\mathrm{Co}=1 \mathrm{mg} / \mathrm{L})$

Micro column rapid breakthrough run curves of MTBE adsorption in continuous flow rate breakthrough experiment: Using the MCRB method, the essential MTBE breakthrough curve was obtained in $<15 \mathrm{~h}$ relative to $>1$ 
week using the conventional breakthrough method. 15 MCRB runs were performed employing 0.3-0.5 g of two coal (F300, SYC), two coconut (GCN830, SYK) and three bamboo (JHBG1, JHBG2 and SBG) GAC samples of 120-180 mesh particles to remove MTBE from tap water and well water influent containing $0.93-1.3 \mathrm{mg} / \mathrm{L}$ of MTBE at two EBCT of 5 and $10 \mathrm{~s}$ (equivalent to 8-16 min of EBCT in full scale treatment $\left.{ }^{13}\right)$; the operating parameters and treatment performance obtained from the MCRB curves (Figs. 4-6) are listed in Table-2.

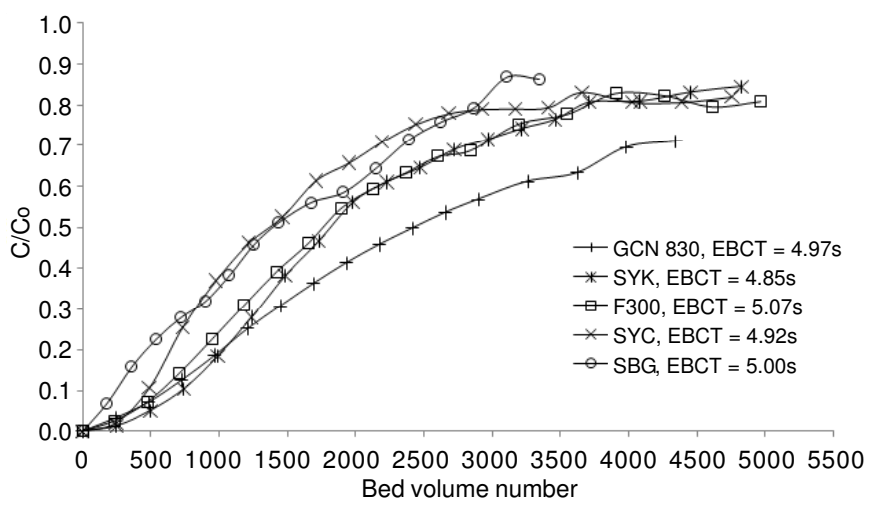

Fig. 4. MCRB curves of MTBE in well water samples

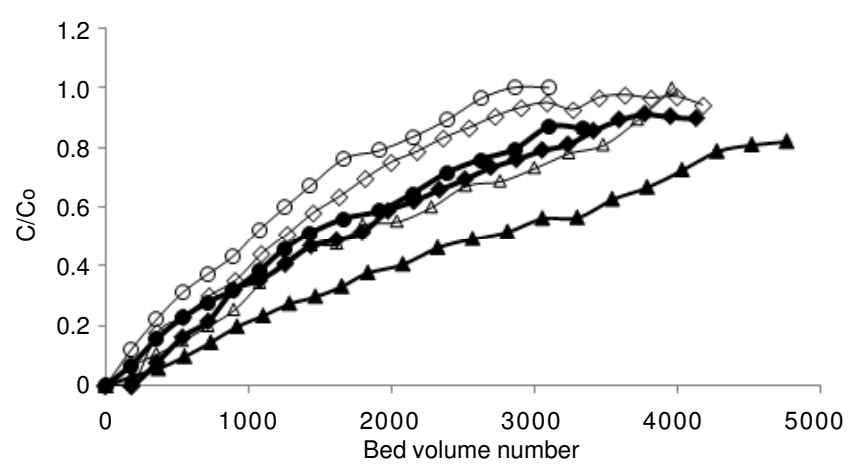

\-JHBG1 in well water, EBCT $=4.91 \mathrm{~s} \triangle \mathrm{JHBG} 1$ in tap water, $\mathrm{EBCT}=5.00 \mathrm{~s}$ JHBG2 in well water, EBCT $=5.03 \mathrm{~s} \checkmark \mathrm{JHBG} 2$ in tap water, $\mathrm{EBCT}=5.03 \mathrm{~s}$ $\mathrm{SBG}$ in well water, $\mathrm{EBCT}=5.00 \mathrm{~s}-\mathrm{SBG}$ in tap water, $\mathrm{EBCT}=4.96 \mathrm{~s}$

Fig. 5. MCRB curves of 3 bamboo GACs

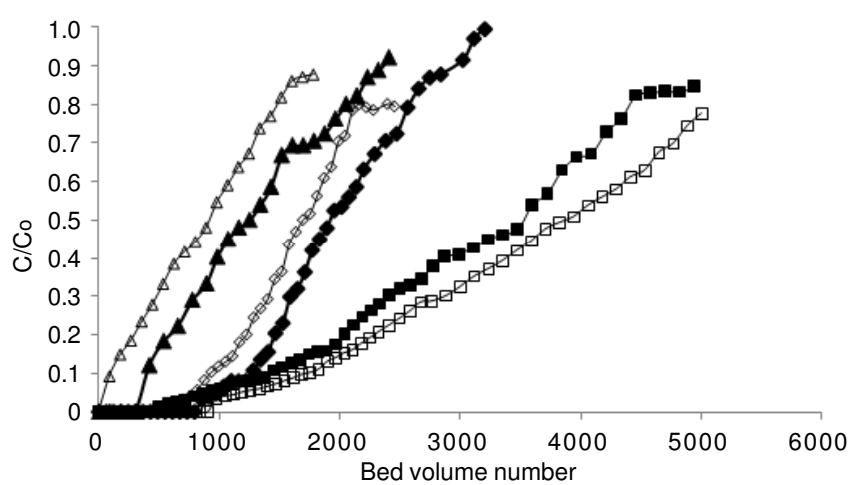

$\square-\mathrm{GCN} 830$ in tap water, EBCT=10.17s $-\mathrm{GCN} 830$ in well water, EBCT=9.82s $\neg$ F300 in tap water, EBCT=10.06s $\neg-\mathrm{F} 300$ in well water, EBCT=9.87s $\triangle \mathrm{SBG}$ in tap water, EBCT $=10.1 \mathrm{~s} \quad \longrightarrow$ SBG in well water, EBCT $=10.1 \mathrm{~s}$

Fig. 6. MCRB curves of MTBE in tap water and well water samples (EBCT $\approx 10 \mathrm{~s})$

The data have clearly demonstrated that the order of MTBE removal of the MCRB runs was the same order of the GACs' isotherm capacities for MTBE and that the capacity utilization was dependent on the GAC type, EBCT and more importantly the max allowable effluent concentration, $\mathrm{Ct}$. While only a small fraction of the available adsorptive capacity was utilize in all runs at $\mathrm{Ct} / \mathrm{C}_{\text {in }}$ of 0.02 ; most capacity were utilized when $\mathrm{Ct}$ was increased to 0.7. Based on the data for the EBCT of $5 \mathrm{~s}$ vs. $10 \mathrm{~s}$ runs for the $\mathrm{C} / \mathrm{C}_{\text {in }}$ of 0.02 and 0.5 series, the capacity utilization would gained only modestly when an adsorber twice as large is employed. Such results have demonstrated that the two serial adsorbers mode of treatment is much most cost effective than using a single adsorber containing the combined amount of GAC since the higher $\mathrm{Ct}$ of the first adsorber effluent can ensure a high utilization of the GAC's available adsorptive capacity while the second adsorber can assure the high quality final effluent.

Fig. 3 data show that the order of the overall MTBE removal effectiveness of GCN830 $>$ SYK $\geq$ F300 $>$ SBG $\geq$ SYC was the same as the order of their phenol numbers. Figs. 5 and 6 show that, except for the GCN830, more MTBE was removed from the higher TOC well water influent than the comparable runs of the tap water influent because the large organic ingredients of well water do not migrate to the adsorption sites in micro pores and thus resulted in less capacity reduction relative to the smaller organic ingredients of the tap water. The results have confirmed the isotherm data depicted in Fig. 3 and are consistent with the finding of our recent study on GAC treatment for removing trichloroethylene ${ }^{21}$.

The good performance of the three bamboo GACs (respectable capacity and utilization rates) has validated their potential applications in groundwater remediation by GAC adsorption. Fig. 5 data show that the two newer JHBG1 and JHBG2 performed better than SBG, which was more cost effective than several coal and coconut GACs in removing trichloroethylene ${ }^{21}$; therefore, with further R and D to improve the physical properties and make them more effective, the environmental friendly bamboo GACs will likely be the most desirable GACs for many water and wastewater treatment applications.

Granular activated carbon adsorption for removing MTBE from newly contaminated groundwater: Table-3 summaries the Freundlich models of the MTBE isotherm data, the relative adsorptive capacities and the minimum exhaustion rates of 7 GACs in removing MTBE from the groundwater at the varying effluent concentrations $(0.5,1,3$ and $8 \mathrm{mg} / \mathrm{L})$. Using the most effective JHBG1 to fill two 4000-L serial adsorbers (3000 L filled at $450 \mathrm{~g} / \mathrm{L}$ ) to clean up a groundwater influent containing $8 \mathrm{mg} / \mathrm{L}$ of MTBE at a total treatment time of $40 \mathrm{~min}$ (EBCT of $20 \mathrm{~min}$ in each adsorber, flowrate $=150$ $\mathrm{L} / \mathrm{min}$ ) and assuming an isotherm adsorptive capacity of 20.28 $\mathrm{mg} / \mathrm{g}$ (minimum carbon exhaustion of $0.39 \mathrm{~g} / \mathrm{L}$ ) and a capacity utilization rate of $80 \%$ for the leading adsorber, the adsorber should be recharged every two weeks (with $1350 \mathrm{~kg}$ of new JHBG1 capable of removing about $22 \mathrm{~kg}$ of MTBE) to ensure an odor free final effluent of $<20 \mathrm{ppb}$ in MTBE. Using the least effective SYC with an adsorptive capacity of $4.35 \mathrm{mg} / \mathrm{g}$ (minimum carbon exhaustion rate of $1.84 \mathrm{~g} / \mathrm{L}$ ), the leading adsorber will have to be recharged twice a week. Because treating a larger body of groundwater containing a lower MTBE concentration is more costly due to the higher GAC 
consumption, a small body of groundwater contaminated with MTBE should be treated by GAC adsorption without delay.

Since MTBE is not well adsorbed, using GAC to remove MTBE by adsorption alone will be too costly except for cleaning up a small body of newly contaminated groundwater having a relatively high MTBE concentration. In actual adsorption remediation of a MTBE contaminated groundwater, the MTBE degrading soil bacteria retained in the adsorber may become more acclimated and grow actively to result in the desirable biological activated carbon function, which will enables long term service of the adsorber without needing periodic GAC replacement due to in situ biological regeneration $^{25}$, making the treatment much more cost effective than when adsorption is the only mechanism of MTBE removal.

\section{Conclusion}

The initial MTBE concentration had no effect in the pure water isotherms; its notable effect in the well water isotherms was due to the different TOC \% of MTBE in the well water solutions. The order of GACs' capacity for MTBE was the same as the order of their phenol number (the indicator of intraparticle surface/volume of small micropores). The GAC's adsorptive capacity for MTBE was dependent on its raw material and manufacturing process; coconut-based activated carbons had the highest MTBE capacities because they had the most internal surface of small micropores. The GACs' capacities for MTBE in well water and tap water samples were reduced from their respective pure water isotherms; the reductions were dependent on the pore structure as well as the size and quantity of residual organic ingredients of the water sample. For the coconut GCN830 and SYK having low tannic acid numbers, the higher TOC well water sample caused greater reductions because more micropores were blocked; for other GACs, tap water sample caused greater reductions due to competitive adsorption of its smaller NOM components. The new bamboo GACs, produced from the widely available, renewable natural resource in a less polluting process, had competitive MTBE capacities and respectable capacity utilization rates in the adsorption breakthrough runs and thus are attractive candidates for removing MTBE and/or other groundwater contaminants. With further improvements in physical properties, they may become the most desirable GACs for many adsorption treatment applications. The breakthrough data show that the GAC's capacity was only partially utilized in single bed treatment; the serial bed mode of treatment is much more cost effective than using a larger single adsorber containing the combined amount of GAC. GAC adsorption is practical for removing a small quantity of MTBE from groundwater. Establishing biological activated carbon function to achieve stable MTBE biodegradation in the adsorber will enable its long term service with periodic GAC replacement and thus make the treatment much more cost effective than when adsorption is the only mechanism of MTBE removal ${ }^{25}$.

\section{ACKNOWLEDGEMENTS}

This study was performed for the following projects: The Fundamental Research Funds for the Central Universities (WB1014038), Shanghai Natural Science Funds (11ZR1409400) and National Natural Science Foundation of China (41201302). Jun Zuo and Nuo Liu assisted in the experimental runs.

\section{REFERENCES}

1. J. Zou, Petroleium Petrochem. Today, 11, 23 (2003).

2. X. Yu, Ecologic Sci., 22, 257 (2003).

3. I. Fikret, Y. Senem, T. Gulsum and S. Selvi, Water Air Soil Pollut, 204, 155 (2009).

4. P.J. Squillace, J.S. Zngorsk, W.G. Wilber and C.V. Price, Environ. Sci. Technol., 301, 721 (1996).

5. L. Yu, C. Adams and D. Ludlow, J. Environ. Eng., 131, 983 (2005).

6. P. Squillace and M. Moran, Environ. Sci. Techno1., 33, 4176 (1999).

7. B. Qian, Contemporary Chem. Ind., 4, 227 (2001).

8. M. Hawkins and G. Hess, Water. Condit. Purif., 8, 86 (2001).

9. M. Stouffer, Water. Condit. Purif., 43, 34 (2001).

10. A. Rossner and D.R.U. Knappe, Water. Res., 42, 2287 (2008).

11. T. Shih, M. Wangpaichitr and M. Suffet, Water. Res., 37, 375 (2003).

12. W.C. Ying, W. Zhang, Q.G. Chang, W.X. Jiang and G.H. Li, Environ. Prog., 25, 110 (2006)

13. Q.G. Chang, W. Zhang, W.X. Jiang, B.J. Li, W.C. Ying and W. Lin, Environ. Prog., 26, 280 (2007).

14. W. Zhang, Q.G. Chang, W.D. Liu, B.J. Li, W.X. Jiang, L.J. Fu and W.C. Ying, Environ. Prog., 26, 289 (2007).

15. D. Das, N. Das and L. Mathew, J. Hazard. Mater., 184, 765 (2010).

16. J.U.K. Oubagaranadin, N. Sathyamurthy and Z.V.P. Murthyn, J. Hazard. Mater., 142, 165 (2007).

17. D6586-00, ASTM Standards, West Conshohocken, PA: ASTM, pp. 882886 (2000)

18. M. Morley, J. Henke and G. Jr. Speitel, J. Environ. Eng., 131, 29 (2005).

19. J. Sutherland, C. Adams and J. Kekobad, Water. Res., 38, 193 (2004).

20. W.C. Ying, E.A. Dietz and G.C. Woehr, Environ. Prog., 9, 1 (1990).

21. L.Y. Huang, Z.D. Yang, B.J. Li, J. Hu, W. Zhang and W.C. Ying, AIChE J., 57, 542 (2011)..

22. T.C. Schmidt, TRAc Trends Anal. Chem., 22, 776 (2011).

23. B. Ulker, G. Batchimeg, D. Halil and D.G. Dilek, Energ. Convers. Manage., 51, 235 (2010).

24. Q. Li, V.L. Snoeyink, B.J. Marin and C. Campos, Water. Res., 37, 4863 (2003).

25. B.J. Li, Ph.D. Dissertation, East China University of Science and Technology, Shanghai, China (2010). 